Int. J. Electrochem. Sci., 16 (2021) Article ID: 210623

International Journal of

ELECTROCHEMICAL

SCIENCE

$\underline{\text { www.electrochemsci.org }}$

\title{
A Novel High-Fidelity Unscented Particle Filtering Method for the Accurate State of Charge Estimation of Lithium-Ion Batteries
}

\author{
Yanxin Xie ${ }^{1}$, Shunli Wang ${ }^{1, *}$, Carlos Fernandez ${ }^{2}$, Chunmei Yu ${ }^{1}$, Yongcun Fan $^{1}$, Wen Cao ${ }^{1}$ \\ ${ }^{1}$ School of Information Engineering, Southwest University of Science and Technology, Mianyang \\ 621010, China; \\ ${ }^{2}$ School of Pharmacy and Life Sciences, Robert Gordon University, Aberdeen AB10-7GJ, UK. \\ "E-mail: $497420789 @$ qq.com
}

doi: $10.20964 / 2021.06 .38$

Received: 12 February 2021 / Accepted: 3 April 2021 / Published: 30 April 2021

\begin{abstract}
Power Li-ion batteries are one of the core "three powers" systems of new energy vehicles, and its accurate batteries modeling and state prediction have become the core technology of the scientific and technological progress in the industry. This paper takes the ternary Li-ion batteries as the research subject. Aiming at the mathematical expressions of different structural features, innovatively construct a second-order Thevenin equivalent circuit model with autoregressive effect. This model can characterize the internal reaction mechanism of Li-ion batteries and fit the complex electrochemical reactions inside the battery. An improved particle filter model, namely a new high-fidelity unscented particle filter method, is designed and established. By introducing a suitable suggested density function, the model can accurately calculate the mean and variance, solve the particle degradation problem, and find out the Li-ion batteries state of charge, which is suitable for complex charging and discharging conditions. By further improving the theoretical analysis and combining with experiments under different working conditions, this method studies the Li-ion batteries state of charge. The test results show that the average absolute error of the improved equivalent circuit model is reduced by $0.00457 \mathrm{~V}$, and the error rate is stably kept within 1\%, which has the ability to describe Li-ion batteries well. When using the high-fidelity unscented particle filter algorithm to estimate the state of charge of the lithium battery, the robustness of the system is improved, the following effect is better, and the estimation error is controlled within $1.5 \%$, which brings good practical value to the power Li-ion batteries.
\end{abstract}

Keywords: ternary Li-ion batteries; second-order Thevenin model; autoregressive; state of charge; highfidelity unscented particle filter algorithm

FULL TEXT 
(C) 2021 The Authors. Published by ESG (www.electrochemsci.org). This article is an open access article distributed under the terms and conditions of the Creative Commons Attribution license (http://creativecommons.org/licenses/by/4.0/). 